\title{
Letramento político em livros didáticos: por um ensino democrático
}

\author{
Priscila Caxilé Soares \\ Universidade Federal do Ceará (UFC) \\ priscilacaxile@yahoo.com.br
}

\section{Resumo}

O artigo trata da temática do letramento político em duas coleções de livros didáticos do ensino médio, respectivamente dos anos 2013 e 2016. Os objetivos são: a) analisar, comparativamente, a proporção com que o letramento político aparece em atividades de produção textual de duas coleções de livros didáticos de Língua Portuguesa do ensino médio; b) verificar a quantidade proporcional de gêneros textuais que se propõem ao ensino efetivo do letramento político; e c) discutir sobre os dados encontrados em ambas as coleções. Para falarmos sobre letramento político, utilizamos Cosson $(2008 ; 2010 ; 2011)$, e para falarmos sobre a política do livro didático e suas contribuições para o estudo dos letramentos, Batista (2003) e Rojo (2010). Os resultados mostraram que os livros didáticos contribuem para as práticas de leitura e escrita, contudo não verificamos nas atividades de produção textual das edições um direcionamento para o ensino da democracia ou de temáticas que se voltassem para uma formação cidadã. Portanto, concluímos que a abordagem das temáticas e das atividades de produção textual propostas, em sua maioria, não se relaciona com conhecimentos diretamente ligados aos conteúdos sobre leis, organização do poder e de suas instituições, logo não contribuem de modo efetivo para o ensino do letramento político.

Palavras-chave: letramento político; ensino; livro didático.

\begin{abstract}
The article treats the theme of political literacy in two high school textbook collections, respectively, 2013 and 2016. The objectives are: a) to analyze, comparatively, the proportion which political literacy appears in activities of textual production in two collections of Portuguese Language High School textbooks; b) to verify the proportional amount of textual genres that are proposed to the effective teaching of political literacy; and c) to discuss the data found in both collections. To talk about political literacy, we used Cosson $(2008,2010,2011)$ and, to talk about the textbook policy and its contributions to the study of the literacies, Batista (2003)
\end{abstract}


and Rojo (2010). The results showed that the textbooks contribute to reading and writing practices; however, we did not verify in the text production activities of the editions a direction towards the teaching of democracy or themes that were turned to a citizen formation. Therefore, we conclude that the approach about the themes and activities of textual production proposed, in the most part, do not relate to knowledge directly related to the contents about laws, organization of power and its institutions, thus they do not contribute in an effective way to the teaching of the political literacy

Keywords: political literacy; teaching; textbook.

\section{Introdução}

Todos temos ciência da fundamental importância que a escola tem na formação de um cidadão que cumpra com suas funções e compreenda a relevância do seu papel nos vários contextos políticos e sociais que demandam o exercício da cidadania ativa. Contudo, alguns estudos como o de Kahne e Westheimer (2003) sobre letramento político nos Estados Unidos comprovam que o ensino para o exercício da cidadania em consonância com a democracia ainda é considerado uma questão de segunda ordem para as escolas e para os governantes. Em vista disso, observamos que a realidade brasileira também não destoa da americana, visto que nos últimos anos o percentual de investimentos tem sido cada vez menor na área da educação, bem como dos recursos que dela fazem parte, como os livros didáticos. ${ }^{1}$

A partir disso, consideramos relevante verificar se, realmente, o ensino que está sendo ofertado para os educandos contribui de maneira efetiva para esta formação democrática baseada no letramento político. Para este trabalho utilizamos como corpus o livro didático, pois consideramos que é esta ferramenta de ensino e aprendizagem que delimita um conjunto de possibilidades de leituras e de práticas de letramento. Nessa perspectiva, consideramos que, mesmo levando em consideração as práticas de sala de

1 Em 2019, o Ministério da Educação (MEC) bloqueou R\$ 348,4 milhões que deveriam ser aplicados na produção, na aquisição, na distribuição de livros e de materiais didáticos e pedagógicos da Educação Básica, conforme matéria publicada no jornal O Globo. Disponível em: https://oglobo.globo.com/sociedade/bloqueiode-3484-milhoes-do-mec-sera-em-livros-didaticos-23860815. Acesso em: 14 abr. 2020. 
aula dos professores e as instruções que estes dão durante a abordagem do livro didático, ainda assim a seleção dos textos feita pelos autores e pelos editores dos materiais didáticos influencia diretamente no ensino e na aprendizagem do educando. Logo, este trabalho parte do seguinte questionamento: os livros didáticos estão colaborando para o desenvolvimento do letramento político?

Nas recentes abordagens sobre letramento, em especial as ligadas aos Novos Estudos do Letramento, têm-se apontado para novas práticas de leitura e escrita e de uso da língua/linguagem em geral nas sociedades letradas e têm-se insistido no caráter sociocultural e situado das práticas de letramento. Logo, isso implica o reconhecimento dos múltiplos letramentos que, de acordo com Street (2003), variam no tempo e no espaço, mas também são contestados nas relações de poder. Voltando para nosso artigo, buscaremos, aqui, analisar a recorrência do letramento político em livros didáticos. Esse tipo de letramento insere-se no campo dos letramentos “dominantes", conforme Hamilton (2002), pois está relacionado a uma organização formal, isto é, a escola. Para tanto, partiremos de nossos objetivos, a saber: a) analisar, comparativamente, a proporção com que o letramento político aparece em atividades de produção textual em duas coleções de livros didáticos de Língua Portuguesa do ensino médio; b) verificar a quantidade proporcional de gêneros textuais que se propõem ao ensino efetivo do letramento político; e c) discutir sobre os dados encontrados em ambas as coleções. As duas coleções de livros didáticos escolhidas como corpus circularam nas escolas da rede pública estadual de ensino médio (1ํㅜㄴ $2^{\circ}$ e $3^{\circ}$ ano), e duas opções foram disponibilizadas pelo Programa Nacional do Livro Didático (PNLD) nos anos de 2014 e 2017.

Os professores puderam escolher entre ambas as coleções a que considerassem de melhor qualidade para ser adotada em sala de aula. $\mathrm{O}$ interesse particular, neste artigo, pelas atividades de produção textual ocorreu porque é a parte em que é dada mais ênfase ao discurso do próprio educando no que concerne não só à produção de gêneros escritos, mas também à produção de gêneros orais.

Tomaremos o letramento político como "o processo de apropriação de práticas, conhecimentos e valores para a manutenção e aprimoramento da democracia" (COSSON, 2010, p. 30). Propomos apresentar um estudo comparativo com livros didáticos de Língua Portuguesa do ensino médio adotados em uma escola da rede pública estadual de ensino médio. 
Compararemos duas edições de anos diferentes da editora SM, mas de mesma autoria, dos três anos do ensino médio ( $1^{\circ}, 2^{\circ}$ e $3^{\circ}$ ) e, em seguida, verificaremos a quantidade proporcional de gêneros textuais que se propõem ao ensino efetivo do letramento político e depois discutiremos os dados encontrados em ambas as coleções.

Para analisar nosso corpus, utilizaremos Cosson $(2008 ; 2010 ; 2011)$ para discutir sobre letramento político, e sobre a política do livro didático utilizaremos Batista (2003) e Rojo (2010).

Para efeito de uma melhor sistematização deste artigo, o organizamos nas seguintes seções: a primeira refere-se ao letramento político, ou seja, sua definição e o que é necessário ensinar para o desenvolvimento dessa educação que colabore e fundamente uma pedagogia do letramento político dentro e fora da escola; a segunda seção refere-se ao livro didático e aos letramentos; a terceira seção refere-se à análise e à metodologia de análise; e a quarta seção, à análise e à discussão dos resultados feitas com base na comparação das duas coleções de livros didáticos. Por fim, a quinta seção refere-se à conclusão dos resultados.

\section{Letramento político: por um ensino democrático}

$\mathrm{Na}$ atualidade, as abordagens mais recentes sobre letramentos têm apontado para as práticas sociais de leitura e escrita e o uso da língua/linguagem nas mais diversas sociedades letradas. Logo, reconhecer essas diversas práticas sociais é, de acordo com Street (2003), reconhecer os múltiplos letramentos que variam no tempo e no espaço, mas também são contestados nas relações de poder. Para os Novos Estudos do Letramento há uma problematização em relação a essas práticas sociais, pois não há garantia de que esses letramentos se associem a elas, portanto problematiza que tipo de letramento é aceito em qualquer tempo e espaço, "quais letramentos são dominantes e quais são marginalizados ou de resistência" (STREET, 2003, p. 77).

Em relação aos letramentos "dominantes", Hamilton (2002) classifica-os como "institucionalizados", visto que estão associados às organizações formais, tais como a escola, as igrejas, o local de trabalho, o sistema legal, o comércio, a burocracia. A autora os distingue dos letramentos vernaculares (autogerados), contudo não os vê como 
independentes, mas interligados. Caracteriza-os como "parte dos discursos especializados incluídos em comunidades de práticas, padronizados e definidos em termos dos propósitos formais da instituição, ao invés de pelos propósitos múltiplos e integrados dos cidadãos e de suas comunidades" (HAMILTON, 2002, p. 4).

Os letramentos dominantes envolvem agentes (professores, autores de livros didáticos, legisladores e especialistas) e são poderosos na proporção do poder das instituições às quais estão vinculados. Por sua vez, os letramentos vernaculares não são controlados ou sistematizados por instituições ou organizações sociais, porém têm sua origem nas culturas locais. Certeau (1994) afirma que esses letramentos são frequentemente desvalorizados e são práticas de resistência ou táticas.

Nessa divisão, o letramento político classifica-se como um "letramento dominante", logo o conteúdo que se supõe necessário a esse tipo de letramento, de acordo com Cosson (2011), é geralmente relacionado ao funcionamento do Estado, com ênfase para os mecanismos democráticos, o que envolve, por um lado, um conhecimento sobre eleições, partidos e instituições, e, por outro, os direitos e os deveres. No entanto, fazemos uma ressalva, pois compreendemos que tal letramento favoreceria, em alguns casos, a manutenção das relações de poder existentes, pois o educando estaria aprendendo uma prática de letramento voltada para a manutenção do Estado Democrático de Direito, do qual atualmente fazemos parte e que, infelizmente, muitas vezes não coincide para que o cidadão perceba que esse exercício de cidadania realmente seja em prol de políticas públicas sociais que colaborem para a consecução de uma sociedade livre, justa e solidária. Entretanto, essa é uma discussão que não cabe neste trabalho, pois requer um maior aprofundamento sobre vários outros assuntos que perpassam os estudos de letramento político, como cidadania e democracia, e tais conceitos não fazem parte dos objetivos propostos aqui.

De maneira mais sintética, ensinar letramento político é conhecer como a organização de poder se auto-organiza, como organiza o funcionamento da sociedade e, sobretudo, como funciona o exercício democrático em sociedade. Carvalho (2002) afirma que para obter conhecimento sobre os valores e os princípios morais dessa formação ética e cidadã nas escolas pode-se consultar a Constituição. O uso desse e de outros documentos como conteúdo costuma ser criticado, tendo em vista o caráter 
formal e informativo que esse ensino pode adquirir. Porém, Carvalho ressalta que

A educação de valores fundamentais à vida pública não pode consistir meramente na transmissão de informações, tais como o conteúdo da Declaração dos Direitos do Homem ou os princípios da Constituição da República, mas sim em práticas efetivas que não podem ser restritas a uma disciplina ou curso, pois a posse dessas informações pode desempenhar um papel fundamental na elaboração de conceitos e práticas vinculados à educação para a cidadania. Mas sua mera tematização não garante uma ação educativa vinculada a esses valores (CARVALHO et al., 2004, p. 435).

Nesse sentido, os professores de Língua Portuguesa, bem como os das demais disciplinas, também seriam responsáveis por ensinar esses conhecimentos ligados ao letramento político em seus conteúdos, favorecendo assim uma abordagem mais diversificada e interdisciplinar dessas práticas de letramento.

Ademais, conforme Cosson (2011), os defensores da educação para a cidadania global e da educação para a cidadania multicultural argumentam que o letramento político não pode ficar restrito aos limites nacionais dados pela Constituição sob o risco de se prender a paroquialismos, perdendo de vista contextos sociais, políticos e econômicos mais amplos; nem restrito a uma visão liberal, generalista ou abstrata dos direitos humanos que ignore as lutas pelo reconhecimento das diferenças e da igualdade de direitos de grupos sociais. Assim, para vencer essas restrições sobre o que ensinar ao promover letramento político, o Centro para Educação Multicultural da Universidade de Washington convidou especialistas para elaborarem princípios e conceitos para o ensino da democracia que pudessem servir de guia para professores e todos aqueles que desejassem promover a democracia por meio de programas educativos.

Os trabalhos coordenados por James A. Banks sintetizam as principais contribuições para a formação de um cidadão na era global. $\mathrm{O}$ texto Democracia e desenvolvimento (BANKS et al., 2005) apresenta quatro princípios e dez conceitos sobre educação para a cidadania. Três desses princípios estão reunidos em uma seção que se refere aos direitos humanos, à interdependência derivada da globalização e ao equilíbrio entre unidade e diversidade nas relações sociais, tudo isso tanto no nível local quanto no 
nacional e no mundial. O quarto princípio é uma repetição sobre o ensino da democracia e suas instituições, porém acrescido do ensino de práticas efetivas de democracia para que o conhecimento adquirido não seja apenas teórico.

Os dez conceitos estão dispostos da seguinte forma: nas três primeiras seções iniciais, que se referem aos três primeiros princípios, há uma reflexão sobre as novas direções do letramento político. Essa característica fica evidente nos dez conceitos que especificam os quatro princípios. Cosson (2011) apresenta os dez conceitos, sendo que o primeiro diz respeito à democracia, que deve ser entendida não somente como um regime político, mas também como um modo de organização social, democracia cultural, seguindo a proposta de Dewey (1939) ao falar sobre democracia criativa. $\mathrm{O}$ segundo conceito refere-se à diversidade, que vai das diferenças de classes sociais à religião, passando por gênero, orientação sexual, etnia, língua e necessidades especiais, as quais devem ser reconhecidas em uma sociedade democrática multicultural. $O$ terceiro conceito refere-se à globalização, que deve ser definida para além dos aspectos econômicos, como interconexão e interdependência entre as pessoas e a maneira como elas vivem no mundo. O quarto conceito refere-se ao desenvolvimento sustentável, que parte da necessidade de desenvolver-se economicamente sem comprometer os recursos futuros, além de chegar às desigualdades de distribuição do planeta. $O$ quinto diz respeito ao imperialismo, que abarca também seus correlatos, a exemplo de colonialismo eletrônico, e outras relações entre as nações para que se compreenda o lugar da democracia nesses contextos. O sexto conceito é o da discriminação acompanhada do preconceito e do racismo, que se encontram disseminados nos níveis interpessoal, intergrupal e institucional e ferem o princípio da igualdade, que define a democracia. $O$ sétimo refere-se à imigração, que leva pessoas e grupos a se deslocarem entre países, o que demanda uma nova compreensão da cidadania. $\mathrm{O}$ oitavo conceito refere-se à identidade e seu reverso, a identidade que aborda as várias formas de se construir o pertencimento em uma comunidade, e o reconhecimento dessas diferentes identidades é parte essencial da tolerância e do respeito que devem imperar em uma sociedade democrática. O nono conceito, resumidamente, refere-se às múltiplas perspectivas com que cada tema ou fenômeno deve ser analisado, promovendo uma visão equilibrada que sustenta o respeito às diferenças ao mesmo tempo e favorece a construção de consensos em uma 
vida em comum na sociedade $\mathrm{O}$ décimo e último conceito refere-se ao jogo entre patriotismo e cosmopolitismo, que busca romper com o etnocentrismo e o paroquialismo, sem deixar de valorizar a identidade nacional.

Tais conceitos, antes de tudo, devem ser vistos mais como um convite para refletir, debater e enfrentar o desafio contemporâneo de se ensinar democracia em países democráticos. Sabemos que tais conceitos são muito mais amplos do que vários programas de cursos que contemplam o letramento político. Porém, vejamos esses conceitos como nortes possíveis de serem ampliados, aprimorados e até mais conscientes de como promover a democracia mediante diferentes possibilidades de atuação no campo do letramento político.

\subsection{Letramento político: como ensinar}

Várias são as maneiras de se ensinar democracia, até mesmo pelas muitas abordagens que o tema propicia. Uma síntese bem conhecida sobre como se ensinar democracia está no relatório A missão cívica das escolas (2003), patrocinado pelo Center for Information and Research on Civic Learning and Engagement e Carnegie Corporation of New York. Nesse estudo, que reuniu 56 especialistas renomados na área, são listadas seis estratégias e abordagens metodológicas que comprovadamente, segundo pesquisas, colaboram para a efetivação da educação cívica: ensinar formalmente o sistema político do país; discutir temas controversos e atuais para os estudantes; levar o aluno a praticar o que aprendeu em sala de aula por meio da atuação em programas comunitários; oferecer atividades extracurriculares que envolvam o aluno no funcionamento da escola ou de sua comunidade; encorajar a participação dos estudantes na gestão escolar; e promover simulações de mecanismos e procedimentos democráticos (CIRCLE, 2003, p. 6).

Outra fonte de pesquisa sobre como abordar o letramento político é o relatório Strategies for learning democratic citizenship, elaborado por Karlheinz Duerr, Vedrana Spajic-Vrkaš e Isabel Ferreira Martins (2000) para o projeto Educação para Cidadania Democrática do Conselho da Europa. Os autores desse relatório, em termos de métodos e práticas, propõem uma distinção de três grupos comumente empregados no letramento político: os métodos baseados na experiência, os métodos baseados na mídia e os métodos baseados na análise. Para os métodos baseados na experiência, as 
estratégias consistem no encontro efetivo com outras pessoas, nos variados tipos de simulação e na produção de textos. Para os métodos baseados na mídia, recomenda-se a leitura crítica das várias formas de mídia, incluídos nessa leitura tanto os conteúdos como as maneiras de comunicar e sua relação com o ensino, assim como o uso da mídia para o ensino, sobretudo aqueles recursos da mídia eletrônica e da internet. Para os métodos baseados na análise, aconselha-se a abordagem de estudos de caso, bem como a análise de textos (jornais, documentos históricos etc.), a análise da mídia e a análise de dados estatísticos.

Em nosso artigo, verificaremos as unidades destinadas ao ensino de produção textual em duas coleções de livros didáticos de Língua Portuguesa intituladas Ser Protagonista, da editora SM para o ensino médio, tendo como foco em nossa análise os métodos e as práticas baseados na experiência, para averiguarmos se há nas atividades de produção textual uma metodologia de ensino voltada para as práticas sociais de leitura e escrita que envolvam a democracia e propiciem a aprendizagem desses conhecimentos ligados ao letramento político.

Democracia é um conteúdo que não pode ser apenas exposto, mas, sobretudo, deve ser experienciado para que seja efetivo e significativo. Democracia é um conteúdo que demanda a participação do educando em práticas sociais, discussão de temas controversos, participação em atividades reais ou simuladas e análise crítica da experiência, para que, assim, seus valores sejam realmente incorporados.

\section{As práticas de letramento por meio do livro didático}

Pesquisas sobre letramentos no Brasil têm apontado que a escola e o livro escolar são colaboradores na constituição e na distribuição de letramentos. Batista (2000) aponta que os livros são um complemento à ação do professor, além disso têm novos formatos que se apresentam coerentes com as interações sociais e as necessidades de jovens e adultos. Nesse sentido, nosso artigo teve como corpus o livro didático, pois concordamos com o referido autor quando diz que, atualmente, o meio de levar práticas letradas para população se dá, sobretudo, por meio dos livros didáticos. Conforme aponta o Inaf, a leitura de livros religiosos e escolares é uma prática bastante difundida de letramento no Brasil. Segundo Ribeiro (2003, p. 7-9), o Inaf, realizado pelo Instituto Paulo Montenegro/Ibope e pela ONG 
Ação Educativa, é uma "pesquisa anual" para fazer um "levantamento nacional sobre o alfabetismo funcional de jovens e adultos", fornecendo "à sociedade brasileira um conjunto de informações sobre habilidades e práticas relacionadas à leitura, escrita e matemática da população brasileira".

Analisando as pesquisas do Inaf de forma mais detalhada, Abreu (2003) nos mostra que há uma relação direta entre a escolarização e o gosto pela leitura, por exemplo. Foi apontado nesse estudo que questionados a respeito de pessoas que influenciaram seu gosto pela leitura, os entrevistados indicam, em primeiro lugar, o professor (37\%), a mãe (36\%) e o pai (24\%), o que aponta para a (esperada) importância da família e da escola na (re)produção das práticas letradas.

Outros dados verificados nesse estudo foram sobre a posse de livros. Somente $15 \%$ da população investigada possui de cinquenta a cem livros ou mais, mas $78 \%$ da população possui entre dez e cinquenta livros. Desses detentores de livros, $50 \%$ compram, $8 \%$ recorrem a bibliotecas e $4 \%$ à escola, resultado que aponta para a ineficácia das bibliotecas e, novamente, para o papel do livro escolar. Esses dados indicam mais uma vez a importância da escola na vida da população, sobretudo da mais carente.

Ademais, esses resultados apontam também para a relevância das políticas públicas do livro escolar (em especial, o PNLD) na (re)produção dos letramentos. Conforme afirma Batista (2003, p. 30), num país como o Brasil, de parcimoniosa distribuição do livro,

[...] o manual didático é um dos poucos gêneros de impresso com base nas quais parcelas expressivas da população brasileira realizam uma primeira - e muitas vezes única - inserção na cultura escrita. É, também, um dos poucos materiais didáticos presentes cotidianamente na sala de aula, constituindo o conjunto de possibilidades com base nas quais a escola seleciona seus saberes, organiza-os, aborda-os.

Portanto, para boa parte da população com acesso à escola, as coletâneas de livros didáticos são o único meio, na maioria das vezes, que a população encontra para se inserir nas práticas letradas de leitura e escrita. Logo, é por intermédio dos livros didáticos que os eventos de letramento em diferentes esferas de comunicação poderão ter lugar. Dessa forma, o letramento político, foco deste trabalho, também tem como meio principal de ensino e aprendizagem o livro didático. 


\section{Metodologia de análise}

A análise que utilizamos é de caráter bibliográfico, pois, de acordo com Fonseca (2002), esse tipo de análise consiste em que as fontes são constituídas por material já elaborado, composto basicamente por livros, no caso desta pesquisa a análise será em livros didáticos. O quantitativo do corpus pertence a duas coleções de livros didáticos de Língua Portuguesa do 1ำ ao 3o ano do ensino médio avaliadas pelo Programa Nacional do Livro Didático (PNLD) nos anos de 2014 e 2017. As coleções são da editora SM, intituladas Ser Protagonista, publicadas nos anos de 2013 e 2016.

As coletâneas das duas edições são compostas por três livros cada uma. Para a análise do corpus verificaremos somente as unidades destinadas ao ensino de produção textual, visto que as duas coletâneas já cumprem com nossos objetivos: a) analisar, comparativamente, a proporção com que o letramento político aparece em atividades de produção textual, esta parte contempla nosso objetivo, tendo em vista que o momento em que aparece na íntegra o discurso do educando é na produção de textos; b) verificar a quantidade proporcional de gêneros textuais que se propõem ao ensino efetivo do letramento político; e c) discutir sobre os dados encontrados em ambas as coleções.

Primeiramente, fizemos uma quantificação das unidades e dos capítulos que se referem à produção textual nos três livros de $1^{\circ}$, $2^{\circ}$ e $3^{\circ}$ ano do ensino médio que compõem as duas edições da coleção Ser Protagonista, anos 2013 e 2016, da editora SM. Em seguida, elaboramos o Quadro 1 para organizar melhor quais os gêneros textuais encontrados em cada uma das edições de livro didático.

Por fim, partimos das seguintes categorias de análise: comparação das atividades de produção textual em ambas as edições de livro didático; quantificação dos gêneros textuais que se propõem ao ensino efetivo do letramento político, buscamos elaborar um agrupamento dos gêneros que apareceram nas duas edições para verificar quantos são os gêneros que aparecem em cada uma das unidades voltadas para o ensino de produção textual. Por fim, a discussão sobre os dados analisados tendo em vista os três métodos de abordagem do letramento político propostos por Karlheinz Duerr, Vedrana Spajic-Vrkaš e Isabel Ferreira Martins (2000). 
Letramento Político em Livros Didáticos...

Quadro 1. Organização dos gêneros textuais encontrados nas edições dos livros didáticos

\begin{tabular}{|c|c|c|c|c|}
\hline Anos e edições & Narrar & Relatar & Expor & Argumentar \\
\hline $1^{\circ}$ ano $(2013)$ & $\begin{array}{l}\text { Conto de } \\
\text { humor }\end{array}$ & $\begin{array}{c}\text { Reportagem } \\
\text { Relato de experiência } \\
\text { vivida }\end{array}$ & $\begin{array}{c}\text { Resumo Comunicação } \\
\text { oral }\end{array}$ & $\begin{array}{c}\text { Dissertação escolar } \\
\text { Carta de reclamação } \\
\text { Mesa-redonda }\end{array}$ \\
\hline $1^{\circ}$ ano (2016) & $\begin{array}{l}\text { Conto de } \\
\text { humor }\end{array}$ & $\begin{array}{c}\text { Reportagem } \\
\text { Relato de experiência } \\
\text { vivida }\end{array}$ & $\begin{array}{c}\text { Resumo Comunicação } \\
\text { oral }\end{array}$ & $\begin{array}{l}\text { Dissertação escolar } \\
\text { Carta de reclamação } \\
\text { Mesa-redonda }\end{array}$ \\
\hline $2^{\circ}$ ano $(2013)$ & Crônica & Perfil biográfico & $\begin{array}{l}\text { Artigo enciclopédico } \\
\text { Artigo expositivo de } \\
\text { livro }\end{array}$ & $\begin{array}{c}\text { Editorial } \\
\text { Resenha crítica } \\
\text { Debate regrado } \\
\text { Fala em audiência pública }\end{array}$ \\
\hline $2^{\circ}$ ano (2016) & Crônica & $\begin{array}{c}\text { Entrevista } \\
\text { Ata de reunião }\end{array}$ & $\begin{array}{l}\text { Artigo de divulgação } \\
\text { científica }\end{array}$ & $\begin{array}{c}\text { Editorial } \\
\text { Resenha } \\
\text { Debate regrado } \\
\text { Fala em audiência pública }\end{array}$ \\
\hline $3^{-}$ano (2013) & $\begin{array}{c}\text { Conto } \\
\text { psicológico }\end{array}$ & $\begin{array}{c}\text { Entrevista } \\
\text { Discurso de orador de } \\
\text { formatura }\end{array}$ & $\begin{array}{c}\text { Seminário } \\
\text { Artigo de divulgação } \\
\text { científica }\end{array}$ & $\begin{array}{c}\text { Anúncio publicitário } \\
\text { Artigo de opinião } \\
\text { Dissertação para o Enem e } \\
\text { para o vestibular }\end{array}$ \\
\hline 3o ano (2016) & $\begin{array}{c}\text { Conto } \\
\text { psicológico }\end{array}$ & $\begin{array}{c}\text { Discurso de orador de } \\
\text { formatura } \\
\text { Currículo } \\
\text { Perfil biográfico }\end{array}$ & Seminário & $\begin{array}{c}\text { Anúncio publicitário } \\
\text { Artigo de opinião } \\
\text { Dissertação para o Enem e } \\
\text { para o vestibular }\end{array}$ \\
\hline
\end{tabular}

Fonte: elaborado pela autora 


\section{Um olhar sobre os livros didáticos: análise e resultados}

Primeiramente, verificamos em nossa análise que a maioria dos gêneros textuais encontrados nas duas edições de livros didáticos intituladas Ser Protagonista, da editora SM, para o ensino médio é de tipologia argumentativa, e que tal tipologia é encontrada nas edições dos três anos do ensino médio, havendo uma preponderância maior desses gêneros argumentativos nas unidades voltadas ao ensino de produção textual. As edições dos anos de 2013 e 2016 deram maior ênfase a esses gêneros textuais, conforme demonstramos no Quadro 1. Percebemos que há um agrupamento de gêneros textuais por unidade em cada uma das edições. $\mathrm{O}$ "agrupamento de gêneros" foi proposto por dois teóricos genebrinos, Schneuwly e Dolz (2004), que o estabeleceram com base nas regularidades linguísticas recorrentes em determinados gêneros, propondo assim uma classificação que compreende cinco eixos: narrar, relatar, argumentar, expor e descrever ações de acordo com os domínios sociais de comunicação estabelecidos como objetivos do processo de ensino-aprendizagem. Percebemos que há quatro eixos em que os gêneros textuais estão agrupados em ambas as edições e que se dispõem na seguinte ordem: narrar, relatar, expor e argumentar.

Foi contabilizado um total de 27 gêneros textuais na edição de 2013 e na de 2016. Ocorreram algumas mudanças de uma edição para outra no que diz respeito ao ano em que seriam abordados alguns gêneros, por exemplo, o gênero artigo de divulgação científica, que era abordado no livro didático do 3ํano na edição de 2013 e deixou de ser abordado na edição de 2016 para este mesmo ano, porém passou a fazer parte do livro do $2^{\circ}$ ano na edição de 2016. Do total de gêneros contabilizados em ambas as edições, vimos que dez são gêneros argumentativos, ou seja, quase $30 \%$ das unidades dos gêneros são do eixo do argumentar.

Sabemos que a argumentação está ligada ao conjunto de ações humanas cuja finalidade é promover a adesão do outro para levá-lo a um determinado comportamento ou aceitação de uma opinião por meio de convencimento e persuasão. Além disso, o ensino de gêneros argumentativos contribui para que sejam desenvolvidas as "habilidades de pensamento", fazendo os indivíduos refletirem sobre sua realidade e agirem sobre ela. De acordo com Camps e Dolz (1995), argumentar constitui, para todos os atores de uma democracia, o meio fundamental para desenvolver suas ideias, para examinar de maneira crítica as ideias dos outros, para rebater os conflitos de 
má-fé e para resolver muitos conflitos de interesse. Logo, essa habilidade a ser desenvolvida por meio dos gêneros argumentativos contribuiria para o ensino das práticas de letramento político. Contudo, quando verificamos a quantidade de gêneros que se propõem ao ensino da democracia, de modo que colaborem para que o educando consiga discutir temas controversos relacionados a atividades extracurriculares, que envolvam o aluno no funcionamento da escola ou de sua comunidade; utilizando-se de mecanismos e procedimentos democráticos, conforme são sugeridas nas estratégias e abordagens do letramento político no relatório (CIRCLE, 2003), percebemos que esses gêneros ainda são ensinados com esse objetivo, na escola, de ensino para uma democracia no ambiente escolar.

Gêneros textuais que estavam presentes e que poderiam ter sido abordados de forma que tratassem de temas controversos e que instigassem o educando a debater sobre eles não foram trabalhados com temáticas que favorecessem tal fim, além de não abordarem um conteúdo relacionado ao conhecimento de leis que estivessem relacionados à referida temática. Vejamos por exemplo a atividade de produção textual do gênero carta de reclamação que aparece em ambas as edições (2013 e 2016) do livro didático do $1^{\circ}$ ano, na Figura 1 .

Em nenhum momento ao longo do capítulo que tratava sobre o gênero carta de reclamação, em ambas as edições, é mencionado algum tipo de informação referente às leis de proteção do consumidor, apesar de na abertura do capítulo, quando há uma definição sobre o gênero a ser estudado, haver o seguinte conceito sobre o gênero carta de reclamação: "É um importante instrumento para o exercício da cidadania e do direito do consumidor". Contudo, não é o que vemos ao longo da abordagem do gênero e da atividade de produção textual que expomos anteriormente, a qual apenas propõe uma reclamação de um produto, serviço ou mesmo da administração pública, porém sem nenhum argumento de ordem legal que colabore para o desenvolvimento dos argumentos durante a elaboração do gênero.

Tal análise nos permite apontar uma abordagem ainda muito imperceptível das práticas sociais que envolvem a democracia de maneira efetiva, com as quais os educandos deveriam estar em contato diariamente. Vemos que mesmo havendo diretrizes de bases educacionais, como os PCN (BRASIL, 1999), que propõem uma educação comprometida com a cidadania, ainda assim, temos dificuldades em relacionar um conhecimento, que deveria se dar, associado às práticas letradas, como a produção textual. 
Figura 1. Carta de reclamação

Produzir uma carta de reclamacão

Proposta

Vocé vai escrever uma carta de reclamaça para ser enviada a uma empresa ou a uma instituiço. Veja o exemplo de algumas situaçóes em que uma carta de reclamaço pode ser enviada.

A. Produto. Se voce comprou um celular que nao funciona adequadamente ou outro produto que veio com defeito, pode escolher reclamar por carta a empresa responsavel pelo produto. Acrescente nessa carta todas as informacoes referentes as tentativas de resolver - problema pessoalmente ou por telefone.

B. Serviço. Se voce esta insatisfeito com sua operadora de internet, ou foi mal atendido em um restaurante, ou viveu qualquer situacão prejudicial ao contratar um servico, pode reclamar por meio de correspondencia. Como voce náo quer arcar com o prejuizo, vai escrever uma carta de reclamaça ao responsavel pela empresa.

C. Administraça publica. Voce percebe em seu bairro algum problema causado pela má ad. ministracao pública? Escreva uma carta de reclamaço a ser encaminhada ao orgà responsavel

\section{Planejamento}

1. Observe no quadro abaixo as características do texto que você vaí produzir.

\begin{tabular}{|c|c|c|c|c|c|c|}
\hline Gênero textual & Público & Finatidade & Meio & Linguagem & Evitar & Inctuir \\
\hline $\begin{array}{l}\text { carta de } \\
\text { rectamaçao }\end{array}$ & $\begin{array}{l}\text { empresa ou } \\
\text { instituição } \\
\text { rectamada }\end{array}$ & $\begin{array}{l}\text { retatar os problemas } \\
\text { ocorridos e } \\
\text { argumentar em favor } \\
\text { de seus direitos }\end{array}$ & $\begin{array}{l}\text { carta } \\
\text { ou } \\
e \rightarrow \text { mait }\end{array}$ & $\begin{array}{l}\text { formal e objetiva: } \\
\text { primeira pessoa do } \\
\text { discurso: formulas } \\
\text { textuais da carta }\end{array}$ & $\begin{array}{l}\text { informaços } \\
\text { vagas, tom } \\
\text { hostii }\end{array}$ & $\begin{array}{l}\text { latos e dados } \\
\text { técnicus do } \\
\text { probiemai grat } \\
\text { para satucto } \\
\end{array}$ \\
\hline
\end{tabular}
2. Defina as dados especificos: marca e modelo do produto, nome da empresa ou instituição.
valores pagos. serviços que seriam realizados, datas e locais dos acontecimentos.

3. O que aconteceu exatamente? Faça uma lista dos fatos que serão apresentados na carta.

4. Defina os argumentos que justificam a reclamaçāo contra a empresa ou instituição.

5. Escolha as fórmulas textuais mais apropriadas para sua carta de reclamação.

6. Copie e complete no caderno o quadro ao lado, preen chendo-o com os dados de seu texto.

Assuntos mais reclamados

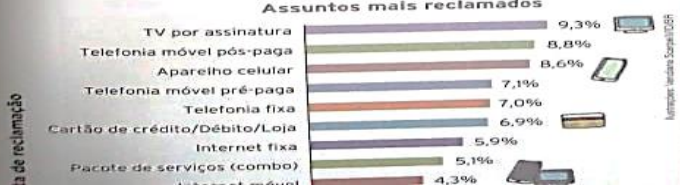

Fonte: RAMOS, 2013, p. 358

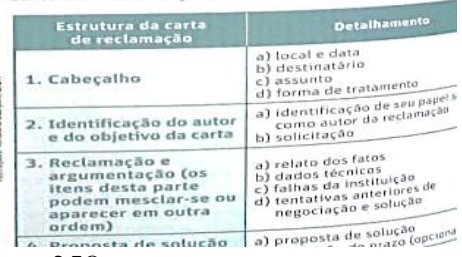

rdem)

Encontramos em alguns capítulos a discussão sobre temas polêmicos, como aquele que trata do gênero artigo de opinião na edição de 2016 do livro didático do $3^{\circ}$ ano. O texto de abertura do capítulo trata da lei do feminicídio, implementada no ano de 2015, conforme observamos na Figura 2. 
Figura 2. Artigo de opinião
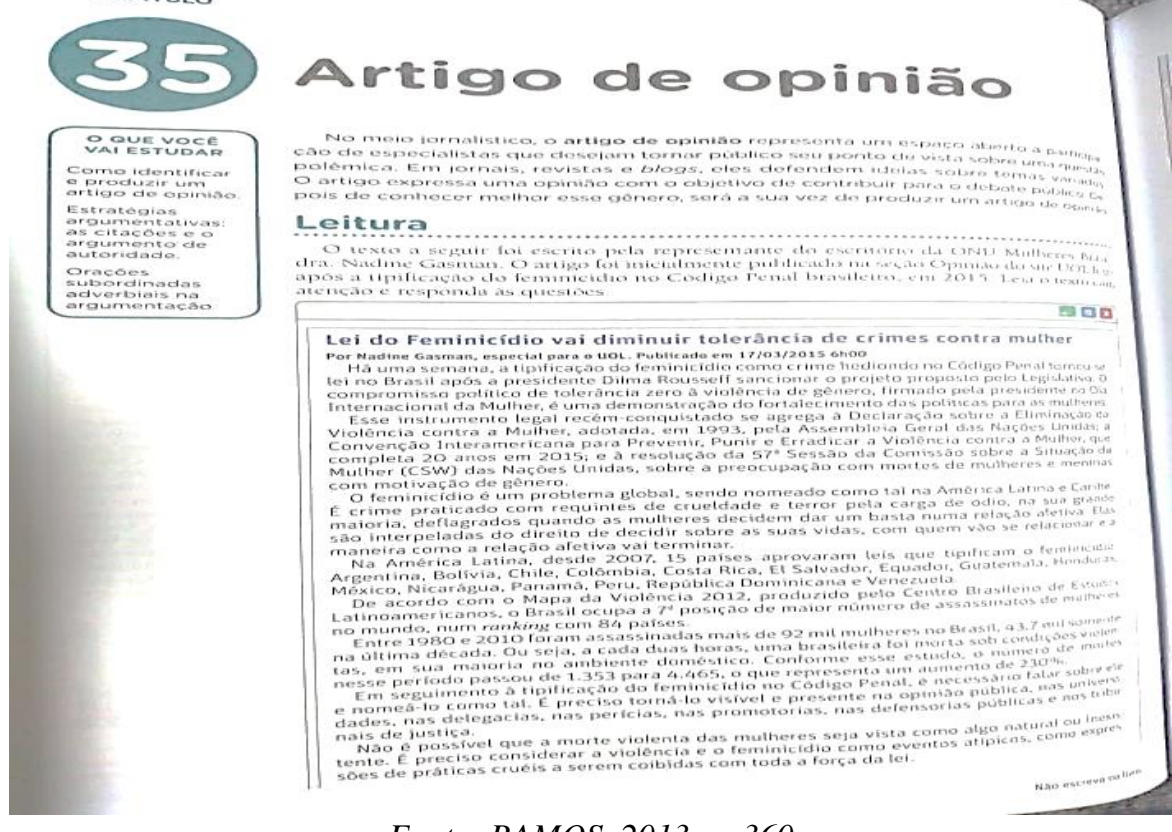

Fonte: RAMOS, 2013, p. 360

No decorrer do capítulo, a temática proposta na atividade de produção textual do gênero artigo de opinião é alimentação saudável. Nos textos da proposta verificamos artigos de apoio retirados de sites como os da Associação Brasileira de Nutrição e do Ministério da Agricultura, conforme mostramos na Figura 3.

Essa atividade demonstra uma relação com o que foi indicado no texto Democracia e desenvolvimento de (BANKS et al., 2005), no qual é proposto como um dos conceitos norteadores para o ensino da democracia o desenvolvimento sustentável, que parte da necessidade de desenvolver-se economicamente sem comprometer os recursos futuros. Vemos que o texto de apoio número 2 da atividade exposta é sobre programas focados no desenvolvimento de produtos orgânicos, retirado do site do Ministério da Agricultura. Isso contribui para que o educando compreenda, como cidadão, as práticas comprometidas com um desenvolvimento sustentável e conheça os programas governamentais voltados para tal iniciativa, propiciando ao 
educando entender a democracia não somente como um regime político, mas também como um modo de organização social e cultural.

Figura 3. Proposta de artigo de opinião

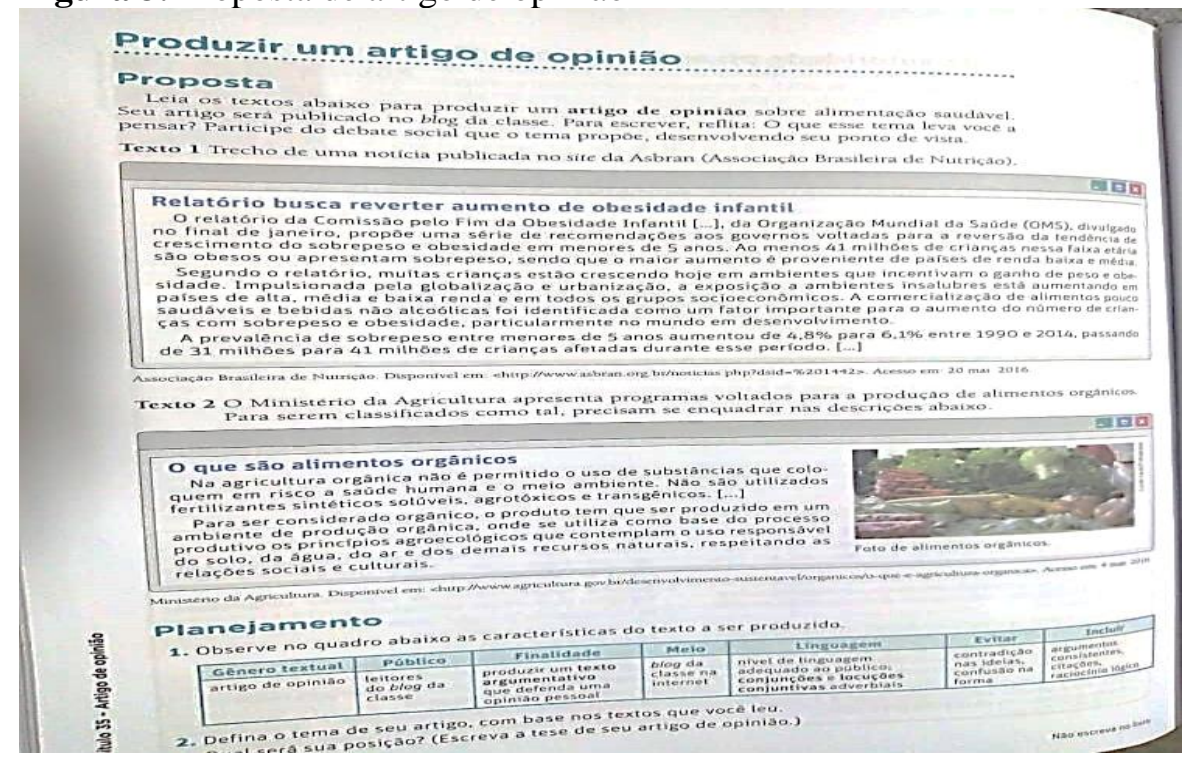

Fonte: RAMOS, 2013, p. 362

Ademais, convém ressaltarmos que o letramento político é recente nos estudos sobre letramento no país e que, como afirma Cosson (2011), ele não depende apenas de conteúdos e metodologias, ainda que estes sejam aspectos essenciais de qualquer processo educativo. Também é importante entender o contexto no qual a democracia é ensinada. O pressuposto é que o ensino formal da democracia é favorecido por um ambiente democrático e vice-versa, o que vai de acordo com o que já dissemos anteriormente - que para aprendermos sobre democracia, precisamos vivenciá-la no cotidiano.

\section{Conclusão}

Concluímos, a partir dos objetivos propostos neste trabalho, que ao analisarmos comparativamente, a proporção com que o letramento político 
aparece em atividades de produção textual nas duas coleções de livros didáticos analisadas aqui, que mesmo havendo um direcionamento nas atividades que proponha a discussão de temas que se relacionem com assuntos da vida escolar e extraescolar do aluno, ainda assim, não há um ensino que efetivamente proporcione uma aprendizagem voltada para formação de um cidadão, interessado pelas questões políticas e que contribua para manutenção da democracia. Além disso, verificamos que a quantidade de atividades propostas nos livros didáticos analisados, que se propunham a um ensino efetivo do letramento político, ainda é bem inferior ao que é sugerido nos documentos que embasam o ensino, como a Lei de Diretrizes e Bases da Educação. Ademais, os dados encontrados nas duas coleções nos mostram que, apesar de uma diversidade de gêneros textuais em ambas as coleções, a abordagem desses textos, bem como a dos temas escolhidos, ainda é pouco direcionada para o ensino comprometido com a cidadania.

Com base no exposto anteriormente, é possível concluir, também, que os textos do eixo argumentativo são muito presentes em ambas as coleções de livros didáticos analisadas, e que mesmo sendo gêneros que contribuem para uma posição e reflexão do educando diante de muitos assuntos que envolvem temáticas de ordem social, ainda assim, não contemplam de maneira efetiva o ensino do letramento político, visto que a abordagem das temáticas e as atividades propostas de produção textual, em sua maioria, não se relacionam com conhecimentos diretamente ligados aos conteúdos de ensino democrático, como o conhecimento sobre leis, organização do poder e instituições do poder.

Como bem afirma Cosson (2011), todo letramento político compreende a disseminação de conhecimentos a respeito de democracia, governo democrático, organização política, instituições e seu funcionamento, Constituição, direitos e deveres da vida em comum, ou seja, conhecimento sobre como a distribuição de poder se organiza e funciona. Contudo, isso não é o que verificamos em nosso breve estudo sobre letramento político em livro didático, que constatou não termos ainda uma proposta de ensino que promova práticas que tratem das habilidades e das competências necessárias ao desenvolvimento do pensamento crítico, à participação decisória, à resolução pacífica de conflitos, ao viver em uma comunidade em que se reconhece igualmente o direito de cada um, em que há respeito pelo outro, bem como diretrizes educacionais que regulem tal ensino. 


\section{Referências}

BATISTA, A. A. G. A avaliação dos livros didáticos: para entender o Programa Nacional do Livro Didático (PNLD). In: ROJO, R. H. R.; BATISTA, A. A. G. (Orgs.). Livro didático de Língua Portuguesa, letramento e cultura da escrita. Campinas: Mercado de Letras, 2003. p. 2568.

BATISTA, A. A. G. Um objeto variável e instável: textos, impressos e livros didáticos. In: ABREU, Márcia (Org.). Leitura, história e história da leitura. Campinas: Mercado de Letras: ALB; São Paulo: Fapesp, 2000.

CAMPS, A.; DOLZ. J. Enseñar a argumentar: un desafio para la escuela actual. Comunicación, Lenguaje y Educación, v. 10, n. 25, p. 5-8, 1995.

CARVALHO, J. S. et al. Formação de professores e educação em direitos humanos e cidadania: dos conceitos às ações. Educação e Pesquisa, v. 30, n. 3, p. 435-445, set./dez. 2004.

CERTEAU, M. de A invenção do cotidiano 1: artes de fazer. 5. ed. Petrópolis: Vozes, 1994.

COSSON, R. Escolas do legislativo, escola de democracia. Brasília: Câmara dos Deputados, Edições Câmara, 2008.

COSSON, R. Letramento político: por uma pedagogia da democracia. Cadernos Adenauer, v. 11, n. 3, p. 25-36, 2010.

COSSON, R. Letramento político: trilhas abertas em um campo minado. ELegis Revista Eletrônica do Programa de Pós-Graduação da Câmara dos Deputados, v. 7, n. 7, p. 49-58, 2011.

DEWEY, J. Creative democracy: the task before us. 1939. Disponível em: $<$ https://www.philosophie.uni-

muenchen.de/studium/das_fach/warum_phil_ueberhaupt/dewey_crea tive democracy.pdf $>$. Acesso em 15 jun. 2020. 
DOLZ, J.; SCHNEUWLY, B. Gêneros orais e escritos na escola. Tradução e organização de Roxane Rojo e Glaís Sales Cordeiro. Campinas: Mercado de Letras, 2004.

FERREIRA MARTINS, I.; DUERR, K.; SPAJIC-VRKA ̌̌, V. Strategies for learning democratic citizenship. Estrasburgo: DGIV/EDU/CIT, Conselho da Europa, 2000. Disponível em: <http://www.storiairreer.it/sites/default/files/norme/2000\%2007\%2019\%20 Duerr.pdf >. Acesso em: 10 jun. 2018.

FONSECA, J. J. S. Metodologia da pesquisa científica. Fortaleza: UEC, 2002.s

HAMILTON, M. Sustainable literacies and the ecology of lifelong learning. In: HARRISON, R. R. F.; HANSON, A.; CLARKE, J. (Org.). Supporting lifelong learning: perspectives on learning. London: Routledge/Open University Press, 2002. v. 1, p. 176-187.

KAHNE, J.; WESTHEIMER, J. Teaching democracy: what schools need to do. Phi Delta Kappan, v. 85, n. 1, p. 34-66, set. 2003.

BRASIL. MINISTÉRIO DA EDUCAÇÃO. Parâmetros curriculares nacionais: Ensino Médio: área de linguagens, códigos e suas tecnologias. Brasília: Secretaria de Educação Média e Tecnológica/MEC, 1999.

RIBEIRO, V. M. Por mais e melhores leitores: uma introdução. In: RIBEIRO, V. M. (Org.). Letramento no Brasil. São Paulo: Ação Educativa/Instituto Paulo Montenegro/Ed. Global, 2003. p. 9-29.

RAMOS, R. A. O livro didático Ser Protagonista de língua portuguesa. 2. ed. São Paulo: Edições SM, 2013.

RAMOS, R. A. O livro didático Ser Protagonista de língua portuguesa. 3. ed. São Paulo: Edições SM, 2016. 
ROJO, R. H. R. Letramentos escolares: coletâneas de textos nos livros didáticos de língua portuguesa. Perspectiva, Florianópolis, v. 28, n. 2, p. 433465, jul./dez. 2010. Disponível em: <https://periodicos.ufsc.br/index.php/perspectiva/article/view/2175795X.2010v28n2p433/18444.> Acesso em: 10 jun. 2018.

STREET, B. V. What's "new" in new literacy studies? critical approaches to literacy in theory and practice. Current Issues in Comparative Education, v. 5, n. 2, p. 77-91, 2003.

CIRCLE (Center for Information and Research on Civic Learning and Engagement). The civic mission of schools: a report from Carnegie Corporation of New York and CIRCLE: The Center for Information and Research on Civic Learning and Engagement. 2003. Disponível em: <https://media.carnegie.org/filer_public/9d/0a/9d0af9f4-06af-4cc6-ae7d71a2ae2b93d7/ccny_report_2003_civicmission.pdf >. Acesso em: 23 jun. 2020.

Recebido em: 01/08/2019

Recebido em versão corrigida: 17/04/2020

Aceito em: 08/05/2020

Title: Political literacy in coursebooks: for democratic education 